\title{
Chalcogen Bond versus Weak Hydrogen Bond: Changing Contributions in Determining the Crystal Packing of [1,2,5]- Chalcogenadiazole-Fused Tetracyanonaphthoquinodimethanes
}

\author{
Yusuke Ishigaki ${ }^{a}$ (D) \\ Kota Asai ${ }^{a}$ (D) \\ Takuya Shimajiria (i) \\ Tomoyuki Akutagawab (D) \\ Takanori Fukushimac(D) \\ Takanori Suzuki*a $^{*}$ \\ a Department of Chemistry, Faculty of Science, Hokkaido University, Sapporo, \\ Hokkaido 060-0810, Japan. \\ Institute of Multidisciplinary Research for Advanced Materials, Tohoku University, \\ Sendai, Miyagi 980-8577, Japan \\ Laboratory for Chemistry and Life Science, Institute of Innovative Research, Tokyo \\ Institute of Technology, Yokohama 226-8503, Japan \\ tak@sci.hokudai.ac.jp \\ Dedicated to Peter Bäuerle on the occasion of his 65th birthday.
}

Received: 12.01.2021

Accepted after revision: 27.01.2021

DOI: 10.1055/s-0041-1725046; Art ID: om-21-0002oa

License terms: cc)

(c) 2021. The Author(s). This is an open access article published by Thieme under the terms of the Creative Commons Attribution-NonDerivative-NonCommercial License, permitting copying and reproduction so long as the original work is given appropriate credit. Contents may not be used for commercial purposes, or adapted, remixed, transformed or built upon. (https://creativecommons.org/licenses/by-nc-nd/4.0/)

Abstract The crystal structures of a series of tetracyanonaphthoquinodimethanes fused with a selenadiazole or thiadiazole ring revealed that their molecular packing is determined mainly by two intermolecular interactions: chalcogen bond (ChB) and weak hydrogen bond (WHB). ChB between Se and a cyano group dictates the packing of selenadiazole derivatives, whereas the $\mathrm{S}$-based $\mathrm{ChB}$ is much weaker and competes with WHB in thiadiazole analogues. This difference can be explained by different electrostatic potentials as revealed by density functional theory calculations. A proper molecular design that weakens WHB can change the contribution of $\mathrm{ChB}$ in determining the crystal packing of thiadiazole derivatives.

Key words crystal engineering, weak hydrogen bonds, chalcogen bonds, chalcogenadiazoles, tetracyanoquinodimethanes, $\mathrm{X}$-ray analysis

\section{Introduction}

The weak hydrogen bond (WHB) involving less acidic $\mathrm{C}-\mathrm{H}$ groups ${ }^{1}$ than $\mathrm{O}-\mathrm{H} / \mathrm{N}-\mathrm{H}$ groups has been used as a supramolecular synthon in crystal engineering. ${ }^{2}$ This approach takes advantage of intermolecular interactions to determine crystal packing and contributes to the design of new solids with desired physical and chemical properties. ${ }^{3}$ In this regard, the chalcogen bond $(\mathrm{ChB})^{4,5}$ has attracted much recent attention due to the high directionality of the interaction in crystal. In

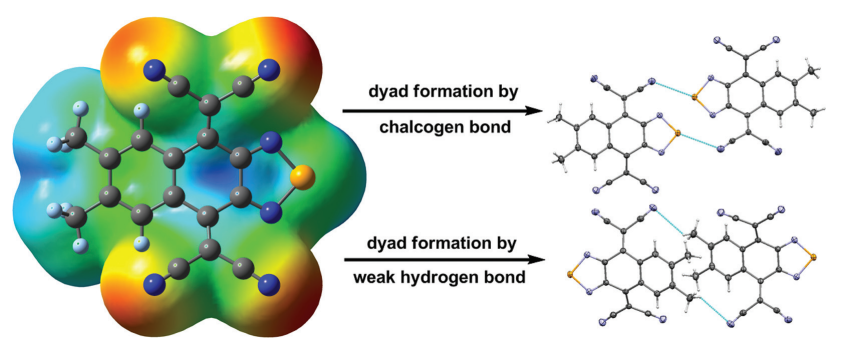

$\mathrm{ChB}$, an electrophilic chalcogen atom (E) is bound to a Lewis base (LB) through $n(\mathrm{LB}) \rightarrow \sigma^{*}(\mathrm{E}-\mathrm{R})$ electron donation in an atomic array of $L B \cdots E-R$, where $R$ is an electron-withdrawing group. The strength of the $\mathrm{ChB}$ is influenced by the nature of the $\mathrm{E}$ atom $(\mathrm{Se}>\mathrm{S}$ ), the nature of the electron-deficient $\mathrm{R}$ group, the LB०.-E-R angle (close to linear), and the basicity of LB. $^{6}$ The directionality of the $\mathrm{ChB}$ was explained by the existence of a $\sigma$-hole on the $E$ atom, which defines a positive electrostatic potential region in the direction opposite the $\mathrm{R}-\mathrm{E}$ bond. [1,2,5]-Chalcogenadiazoles are versatile units $(\mathrm{R}=\mathrm{N}, \mathrm{LB}=\mathrm{N})$ for the generation of supramolecular

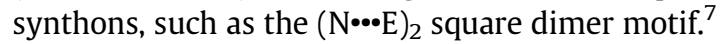

In our continuing studies on the $\mathrm{ChB}$ observed in tetracyanoquinodimethane (TCNQ) derivatives fused with chalcogenadiazole $(\mathrm{s}){ }^{8}$, we noted that the $\mathrm{C} \equiv \mathrm{N} \bullet \bullet$ motif $^{9}$ is often found in these pure organic crystals as $\mathrm{C} \equiv \mathrm{N} \cdots \cdots \mathrm{E}-\mathrm{N}$ contacts, ${ }^{10}$ by which a dyad structure is generated, as shown in Scheme 1a $(R=N, L B=N$ coming from $C N)$. This $C h B$ motif can be used as a reliable supramolecular synthon to make an inclusion cavity in its clathrate compounds. ${ }^{11}$ For example, in the crystal of the title molecule with a selenadiazole ring $(\mathbf{1 A})$, the dyad is further connected into an infinite "dyad-ribbon" network by another ChB. The networks are connected to each other by WHB (Scheme 1b) to complete the overall crystal structure. In a clathrate-type molecular complex of $\mathbf{1 A}$ with an electron-donating guest, the same dyad ribbons are also present, between which the inclusion cavity is formed with breaking of the original WHB and reconnection at different positions with WHB. The resulting three-dimensional cavity endows $\mathbf{1 A}$ with a remarkable ability to recognize the regioisomers of the guest, thus proving the importance of $\mathrm{ChB}$ through the $\mathrm{C} \equiv \mathrm{N} \cdots \cdot \mathrm{Se}-\mathrm{N}$ contact in supramolecular chemisty. ${ }^{12}$ In contrast, despite the similar molecular geometry and electronic structure, the 
a) Dyad formation via ChB motif<smiles></smiles>

b) Dyad formation via WHB motif<smiles></smiles>

c) Polarization increasing $\mathrm{C}-\mathrm{H}$ acidity<smiles></smiles><smiles></smiles>

(unstable $p$-quinodimethane)

Scheme 1 Supramolecular synthons by ChB and WHB.

sulfur analogue (2A) does not show similar recognition properties because WHB through $\mathrm{C} \equiv \mathrm{N} \bullet \cdot \mathrm{H}-\mathrm{C}$ contacts is a predominant factor in determining its crystal packing due to the less-effective $\mathrm{ChB}$ through $\mathrm{C} \equiv \mathrm{N} \bullet \bullet \mathrm{S}-\mathrm{N}$ contacts.

Since $\mathrm{ChB}$-driven molecular recognition is still considered to be in its infancy, ${ }^{13}$ the strikingly different recognition properties between $\mathbf{1 A}$ and $\mathbf{2 A}$ prompted us to further study the molecular packing of other tetracyanonaphthoquinodimethane (TCNNQ) analogues fused with a chalcogenadiazole (e.g., 1B, 1C, 2B, and 2C) (Figure 1). This study sought to clarify whether a change in the chalcogen atom (Se in $\mathbf{1}$ and $S$ in $\mathbf{2}$ ) and/or proper subunit addition could alter the contribution of $\mathrm{ChB}$ in determining the crystal packing of the title molecules, especially in competition with WHB.

\section{Results and Discussion}

For both TCNNQs fused with a selenadiazole (1A) and a thiadiazole (2A), modification should only be done on the

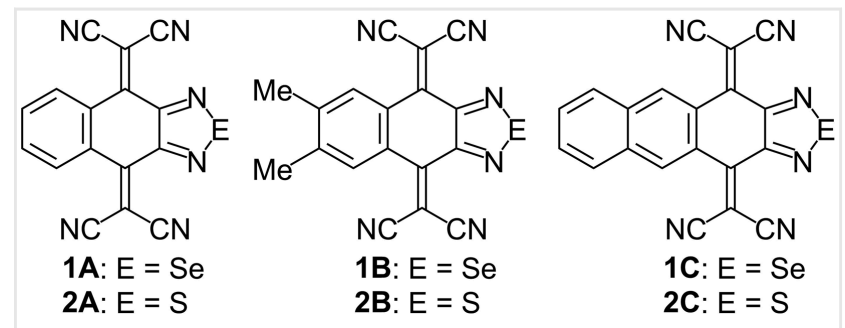

Figure 1 Dimethylation and further benzo-annulation on the TCNNQ skeleton to further weaken WHB in $\mathbf{1 A}$ and $\mathbf{1 B}$. fused benzene ring, so that $\mathrm{ChB}$ would be maintained as in 1A and 2A. We designed here new TCNNQs by attachment of methyl groups at the 6,7-positions (1B and $\mathbf{2 B}$ ) or further annulation of a benzene ring ( $\mathbf{1 C}$ and $\mathbf{2 C}$ ) by considering that such modification affects the WHB motif shown in Scheme $1 \mathrm{~b}$. The carbon hybridization at $\mathrm{C}-\mathrm{H}$ affects the strength of WHB: $\mathrm{C}_{\mathrm{sp} 3}-\mathrm{H}$ is less effective than $\mathrm{C}_{\mathrm{sp} 2}-\mathrm{H}^{14}{ }^{14}$ Thus, WHB would have less of an influence on crystal packing in dimethyl derivative $\mathbf{2 B}$ than in $\mathbf{2 A}$. The acidity of the $\mathrm{C}-\mathrm{H}$ group also determines the strength of $\mathrm{WHB},{ }^{15}$ and the finding that the polar $C$ form has less of a contribution than the polar A (Scheme 1c) suggests that further annulated analogue $\mathbf{2 C}$ has as less effective WHB than $\mathbf{2 A}$. These are the central points of the molecular design, and suggest that the two kinds of modification would increase the contribution of $\mathrm{ChB}$ in determining the crystal packing of $\mathbf{2}$ in comparison to WHB. It is highly likely that all of the crystal structures of selenadiazole derivatives (1) would be dictated by $\mathrm{ChB}$ through $\mathrm{C} \equiv \mathrm{N} \cdots \cdot \mathrm{Se}-\mathrm{N}$ contacts, and thus the molecular packing of $\mathbf{1 A - 1 C}$ can be used as a reference. Thus, a changeable contribution of $\mathrm{ChB}$ and WHB would be clarified when the crystal structures are compared between $\mathbf{1}$ and $\mathbf{2}$ upon weakening of the WHB through dimethylation in $\mathbf{2 B}$ and further benzo-annulation in $\mathbf{2 C}$.

Electrostatic potentials can provide detailed information on molecular polarization. The $V_{s, \max }$ and $V_{\mathrm{s}}$,min values are useful for evaluating of the intermolecular interactions such as ChB and WHB. Density functional theory (DFT) calculations were conducted for 1B, 1C, $\mathbf{2 B}$, and 2C [M06-2X/6$31 \mathrm{G}(\mathrm{d}, \mathrm{p})]$ (Figure $\mathrm{S} 1$ ) and the results were compared to those of $\mathbf{1 A}$ and $\mathbf{2 A}$ calculated using the same function and basis set. ${ }^{12}$ The $6-31 \mathrm{G}(\mathrm{d}, \mathrm{p})$ basis set with a reasonable calculation cost would be satisfactory since the results were compared only among $\mathbf{1 A - 1 C}$ and $\mathbf{2 A - 2 C}$, which have similar geometrical and electronic structures.

As shown in Figure 2, the electrostatic potentials of the present TCNNQs are similar to each other: large positive values on the $\mathrm{E}$ atom corresponding to the presence of $\sigma$ holes and on the $\mathrm{C}-\mathrm{H}$ groups, and large negative values on the $\mathrm{N}$ atoms of cyano groups and those of chalcogenadiazoles. The $V_{\mathrm{s} \text {,max }}$ values on Se in $\mathbf{1 B}$ and $\mathbf{1 C}(+33.3$ and 33.6 $\mathrm{kcal} \mathrm{mol}^{-1}$, respectively) are similar to that in $\mathbf{1 A}(+35.0 \mathrm{kcal}$ $\mathrm{mol}^{-1}$ ). On the other hand, $V_{\mathrm{s} \text {,max }}$ values of the $\mathrm{C}-\mathrm{H}$ groups at the opposite region on the long molecular axis in $\mathbf{1 B}$ and 1C (+25.2 and $27.1 \mathrm{kcal} \mathrm{mol}^{-1}$, respectively) are smaller than those of $\mathbf{1 A}\left(+30.5 \mathrm{kcal} \mathrm{mol}^{-1}\right)$ and the parent TCNNQ without a fused heterocycle $\left(+29.9 \mathrm{kcal} \mathrm{mol}^{-1}\right)$. Thus, ChB should be the predominant intermolecular interaction in $\mathbf{1 B}$ and 1C with an even weaker WHB than in 1A.

Thiadiazole compounds $\mathbf{2 A}-\mathbf{2} C$ have smaller $V_{\text {s,max }}$ values $\left(+28.7,27.0\right.$, and $27.2 \mathrm{kcal} \mathrm{mol}^{-1}$, respectively) on $S$ than on Se in $\mathbf{1 A}-1 \mathrm{C}$, and thus the $V_{\mathrm{s}}$,max value of the $\mathrm{C}-\mathrm{H}$ groups in $\mathbf{2 A}$ $\left(+31.2 \mathrm{kcal} \mathrm{mol}^{-1}\right)$ is larger than them. However, when two methyl groups are attached in $\mathbf{2 B}\left(+25.9 \mathrm{kcal} \mathrm{mol}^{-1}\right)$ and 

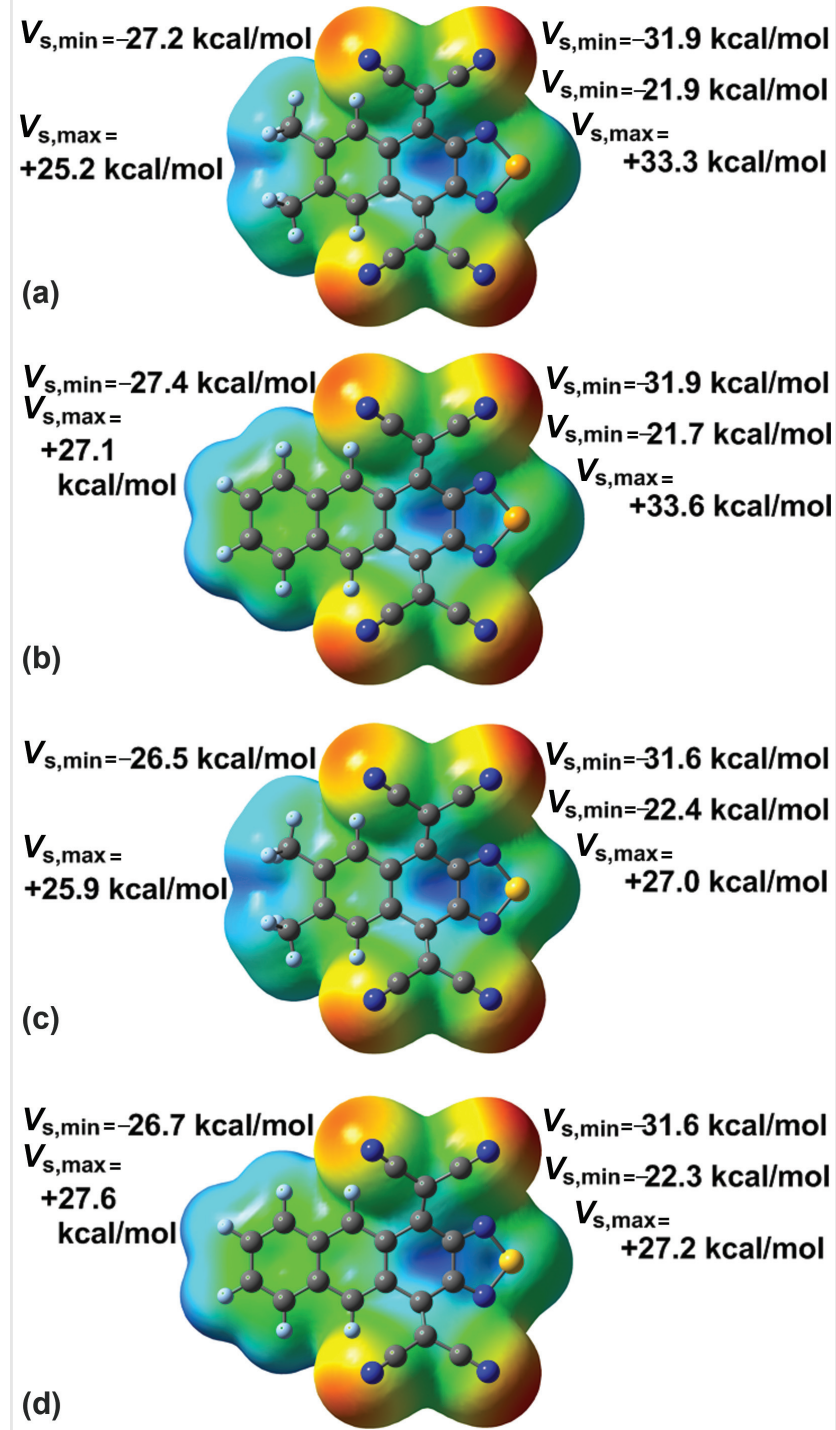

Figure 2 Electrostatic potentials in (a) 1B, (b) 1C, (c) 2B, and (d) $2 \mathrm{C}$ calculated by the DFT method [M06-2X/6-31G(d,p)] (isoval. $=0.0004$ ).

further benzo-annulation is applied in $\mathbf{2 C}\left(+27.6 \mathrm{kcal} \mathrm{mol}^{-1}\right)$, $V_{\mathrm{s}, \max }$ of the $\mathrm{C}-\mathrm{H}$ groups is decreased. Thus, $V_{\mathrm{s}, \max }$ values related to $\mathrm{ChB}$ and $\mathrm{WHB}$ are comparable in $\mathbf{2 B}$ and $\mathbf{2 C}$, and unlike in $\mathbf{2 A}$, both $\mathrm{ChB}$ and WHB should contribute to determining their crystal packing.

After the theoretical studies shown above, newly designed TCNNQs (1B, 1C, 2B, and $\mathbf{2 C}$ ) were prepared from the corresponding quinone derivatives ${ }^{16}$ fused with a chalcogenadiazole ring upon condensation reactions with malononitrile in the presence of $\mathrm{TiCl}_{4}{ }^{17}$ Voltammetric analyses in $\mathrm{MeCN}$ indicated that newly prepared TCNNQs undergo reversible electrochemical reduction $\left(E_{1}{ }^{\text {red }}\right.$ and $E_{2}{ }^{\text {red }} / \mathrm{V}$ vs. saturated calomel electrode (SCE): 1B, -0.37 and -0.48 ; 1C, -0.45 and $-0.55 ; \mathbf{2 B},-0.25$ and $-0.41 ; \mathbf{2 C}-0.35$
Table 1 Geometrical description ${ }^{\mathrm{a}}$ for (a) $\mathrm{ChB}$ of $\mathrm{C} \equiv \mathrm{N} \bullet \bullet \cdot \mathrm{E}-\mathrm{N}$ and (b) WHB of $\mathrm{C} \equiv \mathrm{N} \cdots \cdot \mathrm{H}-\mathrm{C}$ in $\mathbf{1 B}, \mathbf{1 C}, \mathbf{2 B}$, and $\mathbf{2 C}$

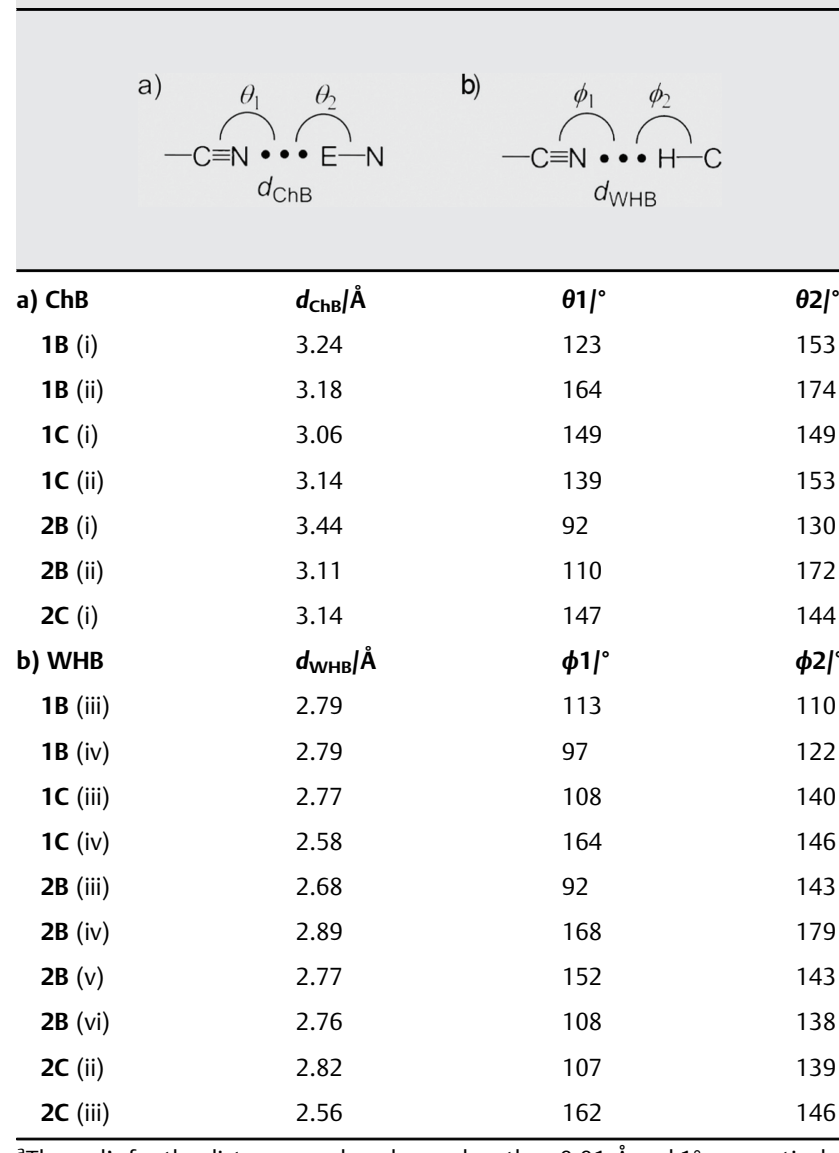

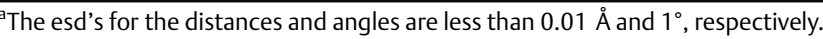

and -0.41) as in other related TCNQ derivatives. The small separation between the first and second reduction potentials as in $\mathbf{1 A}\left(E_{1}{ }^{\text {red }}\right.$ and $E_{2}{ }^{\text {red }} / \mathrm{V}:-0.35$ and -0.46$)$ and $\mathbf{2 A}$ $(-0.22$ and -0.41$)$ indicates that these TCNNQs adopt a butterfly-shaped deformed structure, ${ }^{18}$ which was predicted by calculation (Figure 2) and later revealed by X-ray analyses (Figures S2-S5, Table S1). Recrystallization (vapor diffusion method) from $\mathrm{CH}_{2} \mathrm{Cl}_{2}$-hexane (for $\mathbf{2 C}$ ) or $\mathrm{CHCl}_{3}-$ hexane (others) gave single crystals that were suitable for $\mathrm{X}$ ray analyses as yellow plates (1B and $\mathbf{2 B}$ ) or orange plates (1C and 2C).

Selenadiazolo-TCNNQ with two methyl groups (1B) crystallizes in triclinic $P-1(Z=2)$. The packing arrangement is mainly characterized by two kinds of $\mathrm{ChB}$ through $\mathrm{C} \equiv \mathrm{N} \cdots \cdot \mathrm{Se}-\mathrm{N}$ contacts [(i) and (ii)]. The geometries of $\mathrm{ChB}$ can be described by the distance $\left(d_{\mathrm{ChB}}\right)$ of $(\mathrm{C} \equiv) \mathrm{N} \cdots \cdot \mathrm{E}$ as well as two angles $(\theta 1:<C \equiv N \cdots E ; \theta 2:<N \cdots E-N)$ (Table 1$)$. By the $\mathrm{ChB}$ through contact (i), two molecules of 1B form a centrosymmetric dyad, as shown in Scheme 1a. The dyad is further connected by $\mathrm{ChB}$ through contact (ii) along the crystallographic $b$-axis, thus forming an infinite dyad-ribbon network (Figure 3). The $d_{\mathrm{ChB}}$ values of (i) and (ii) are both 


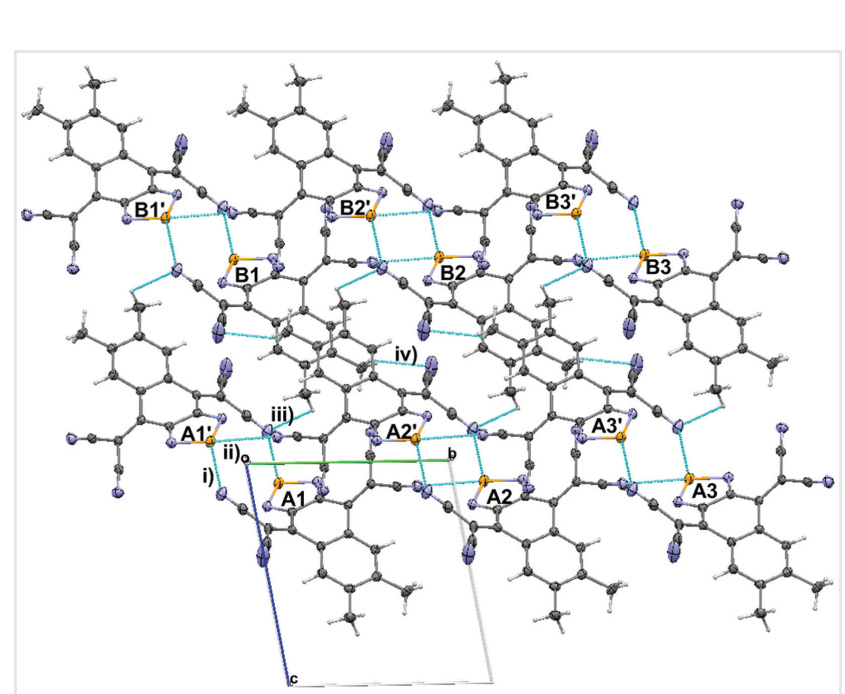

Figure 3 Sheet-like structure composed of dyad-ribbon networks in 1B. Molecules A1 and A1' forms a dyad by ChB through contact (i). Molecules A1, A2, and A3 (as well as A1', A2', and A3') are connected by ChB through contact (ii) to form the dyad-ribbon network. Two dyad ribbons ( $\mathrm{A} 1-\mathrm{A} 3^{\prime}$ and $\mathrm{B} 1-\mathrm{B} 3^{\prime}$ ) are connected by WHB of (iii) and (iv) between $A 1$ 'and $B 1$ and between $A 2$ ' and $B 1$, respectively.

smaller than the sum of the van der Waals (vdW) radii of

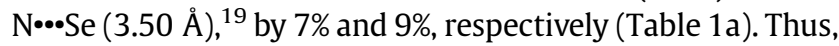
as also supported by suitable contact angles ( $\theta 1$ and $\theta 2$ ), the $\mathrm{ChB}$ is proven to be a strong and important director of the crystal packing of $\mathbf{1 B}$. The positions of hydrogen atoms in $\mathbf{1 B}$ were calculated geometrically, and thus there is some uncertainty regarding the parameters for WHB involving $\mathrm{C}-\mathrm{H}$ of methyl groups. Despite such uncertainty, it is still clear that the dyad-ribbon networks are further connected to each other along the $c$-axis by WHB through $\mathrm{C} \equiv \mathrm{N} \cdots \cdot \mathrm{H}-\mathrm{C}$ contacts of (iii) and (iv) (Table 1b), and thus a two-dimensional sheet-like structure is formed on the $b c$-plane. Since the sheets are repeated along the $a$-axis without significant interaction, the most characteristic feature is the sheet-like structure composed of dyad-ribbon networks. This packing is quite similar to that of 1A (Figure S6) without methyl substitution, ${ }^{12}$ showing that attachment of two methyl groups does not alter the packing motif because strong $\mathrm{ChB}$ through $\mathrm{C} \equiv \mathrm{N} \cdots \cdot \mathrm{Se}-\mathrm{N}$ is the dominant factor in determining the crystal structure in $\mathbf{1 A}$ and $\mathbf{1 B}$.

Selenadiazolo-TCNNQ with further annulation of a benzene ring $(\mathbf{1 C})$ crystallizes in triclinic $P-1(Z=2)$. The packing arrangement is mainly characterized by two kinds of $\mathrm{ChB}[(\mathrm{i})$ and (ii)]. By the contact of $\mathrm{C} \equiv \mathrm{N} \cdots \mathrm{Se}-\mathrm{N}$ (i), two molecules of $\mathbf{1 C}$ form a centrosymmetric dyad, as shown in Scheme 1a. This dyad is further connected by $\mathrm{ChB}$ through

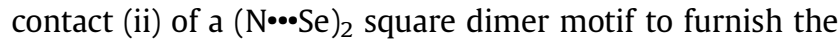
dyad-ribbon network along the crystallographic $b$-axis. The additional contacts of WHB [(iii) and (iv)] are present within the dyad ribbon (Figure $4 \mathrm{a}$ ). In contrast to $\mathbf{1 A}$ and $\mathbf{1 B}$, the dyad ribbons of $\mathbf{1 C}$ are not further connected by WHB since the two
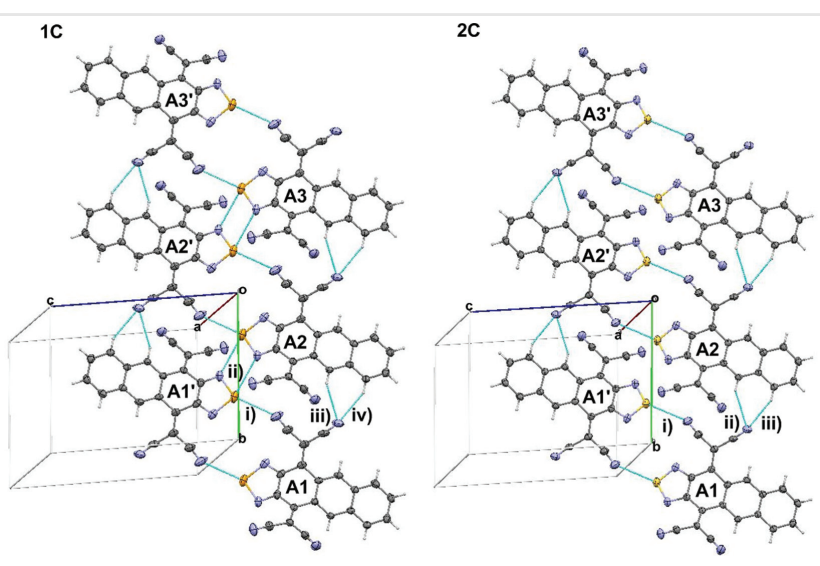

Figure 4 Dyad-ribbon network in $\mathbf{1 C}$ (left) and $\mathbf{2 C}$ (right). Molecules A1 and $A 1$ ' forms a dyad by ChB through contact (i). Dyads are further connected along the $b$-axis to form a dyad-ribbon network (A1-A3').

$\mathrm{C}-\mathrm{H}$ groups at the edge of the long molecular axis are not involved in WHB. Instead, the dyad ribbons are stacked in a layered-brick manner (Figure 5a) with two kinds of $\pi-\pi$ overlaps (type-1: convex-convex; type-2: concave-concave) with the shortest $\mathrm{C}-\mathrm{C}$ contact of 3.32 and $3.35 \AA$, respectively (Figure S3). Thus, the crystal packing of $1 \mathrm{C}$ is governed by $\mathrm{ChB}$ and $\pi-\pi$ interaction, so that the relative importance of WHB in $\mathbf{1 C}$ is even less than those in $\mathbf{1 A}$ and $\mathbf{1 B}$.

The crystal packing of thiadiazolo-TCNNQ with two methyl groups (2B) [orthorhombic, $P c a 2_{1},(Z=4)$ ] is quite different from that in the corresponding selenadiazole derivative 1B. Molecules are connected to form a sheet-like network on the $a b$-plane by WHB (iii) and (iv). There also is a

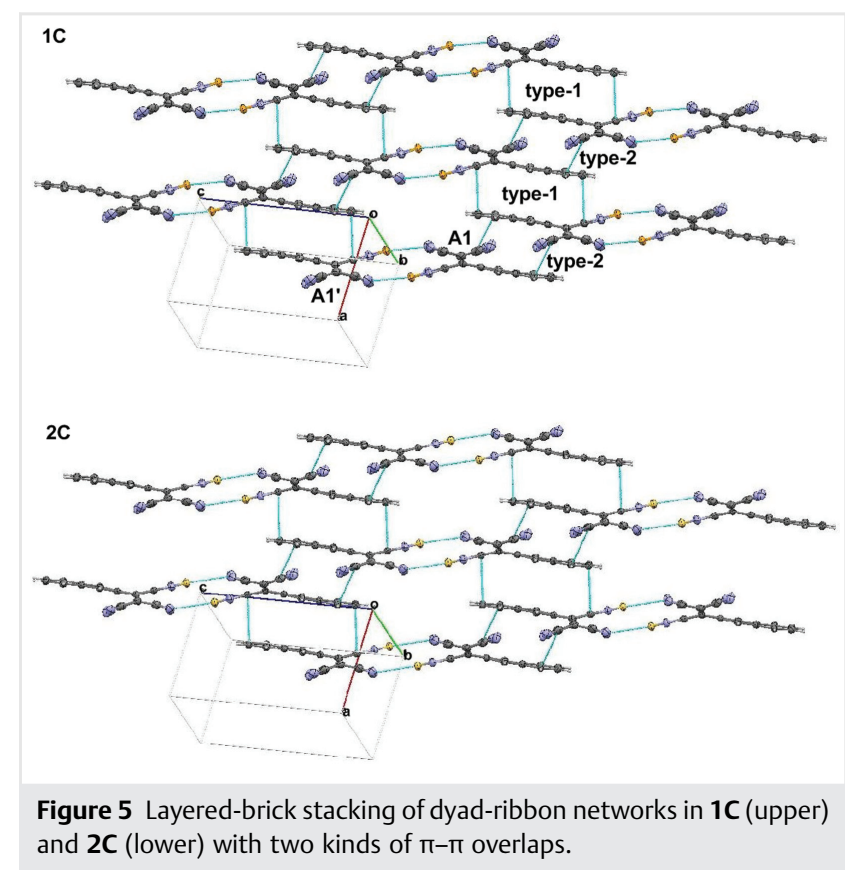




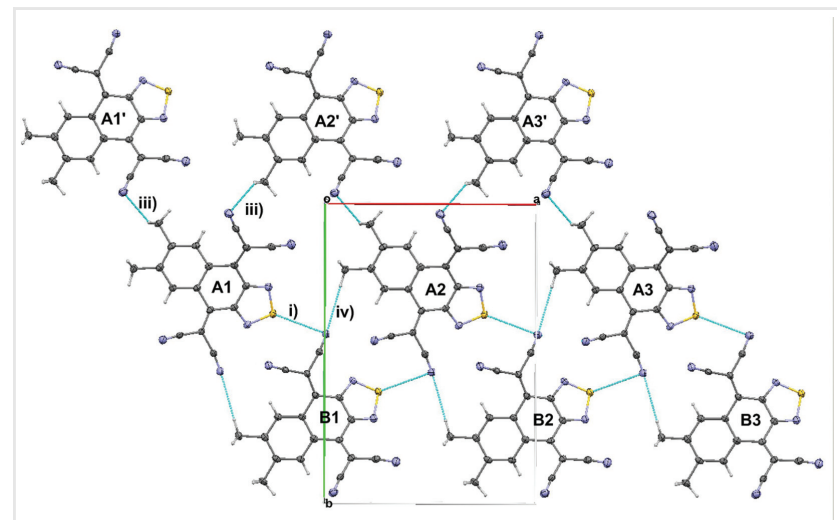

Figure 6 Sheet-like structure of $\mathbf{2 B}$. Molecule A1 is connected to A1' and $A 2^{\prime}$ by WHB through contact (iii) to form a double-ribbon network (A1-A3') along the $a$-axis. This ribbon is connected to another ribbon (B1-B3) by WHB of (iv) and ChB (i) to form a sheet-like network on the ab-plane.

contact of $\mathrm{C} \equiv \mathrm{N} \cdots \cdot \mathrm{S}-\mathrm{N}$ (i) with $d_{\mathrm{ChB}}$ of $3.44 \AA$, which is larger than the sum of the vdW radii of $\mathrm{N} \cdots \cdot \mathrm{S}(3.35 \AA)^{19}$ and would not be considered as an effective $\mathrm{ChB}$ (Figure 6 ). Such a coplanar arrangement of molecules resembles the packing of $\mathbf{2 A}$ in its molecular complex with an electron-donating guest. ${ }^{12}$ Each molecule is further connected along the screw axis extending to the crystallographic $c$-axis. Three kinds of catemer structures are formed not only by the $\mathrm{C} \equiv \mathrm{N} \cdots \bullet \mathrm{S}-\mathrm{N}$ contact (ii) but also by $\mathrm{C} \equiv \mathrm{N} \bullet \bullet \mathrm{C}-\mathrm{H}$ contacts of (v) and (vi) (Figure S4). In this way, the packing arrangement of $\mathbf{2 B}$ is determined by both ChB and WHB.

In contrast, thiadiazolo-TCNNQ with further annulation of a benzene ring $(\mathbf{2 C})$ [triclinic $P-1 \quad(Z=2)$ ] crystallizes isomorphous to $\mathbf{1 C}$ (Figures $4 \mathrm{~b}, 5 \mathrm{~b}$, and $\mathrm{S} 5$ ). Thus, its packing is basically determined by $\mathrm{ChB}$ and $\pi-\pi$ interaction, indicating a reduced contribution from WHB due to weakening via benzo-annulation in $\mathbf{2 C}$. A notable difference is the absence of $\mathrm{a}(\mathrm{N} \cdots \cdot \mathrm{S})_{2}$ square dimer motif in $\mathbf{2 C}$, due to the generally weaker $\mathrm{ChB}$ in thiadiazoles than in selenadiazoles. ${ }^{\text {a }}$

\section{Conclusions}

Based on the above-mentioned four X-ray structures as well as their comparisons including those of $\mathbf{1 A}$ and $\mathbf{1 B}$, we can safely conclude that the contribution of $\mathrm{ChB}$ in thiadiazolo-TCNNQs (2A-2C) is increased by weakening WHB through two different modifications of the molecular structure. By considering that crystal packing of all the selenadiazolo-TCNNQs (1A-1C) is dictated by $\mathrm{ChB}$ and that 2C has an isomorphous structure to that of 1C, a proper molecular design (e.g., further benzo-annulation) should successfully suppress the contribution from WHB while making ChB the decisive factor for packing arrangement.
ChB through $\mathrm{C} \equiv \mathrm{N} \bullet \bullet \mathrm{E}-\mathrm{N}$ contacts is a useful supramolecular synthon in crystal engineering, and thus chalcogenadiazole-fused electron acceptors can recognize the regioisomers of electron-donating guests in their crystalline molecular complexes. ${ }^{11 \mathrm{~d}}$ By following the general trend with stronger interaction for a Se-involving ChB than for a S-involving ChB, thiadiazole-fused acceptors can only provide the less reliable synthon of $\mathrm{C} \equiv \mathrm{N} \bullet \cdot \mathrm{S}-\mathrm{N} .{ }^{12}$ However, by proper design to suppress competing interactions such as WHB, S-involving ChB can become the decisive factor of crystal packing. In this way, this work has demonstrated that the contribution of $\mathrm{ChB}$ in crystal engineering can be altered.

\section{Experimental Section}

${ }^{1} \mathrm{H}$ and ${ }^{13} \mathrm{C}$ NMR spectra were recorded on a BRUKER Ascend ${ }^{\mathrm{TM}} 400\left({ }^{1} \mathrm{H} / 400 \mathrm{MHz}\right.$ and $\left.{ }^{13} \mathrm{C} / 100 \mathrm{MHz}\right)$ spectrometer. IR spectra were measured on a Shimadzu IRAffinity-1S FT/IR spectrophotometer in ATR mode. UV/Vis spectra were recorded on a Hitachi U-2910 spectrophotometer. Mass spectra were recorded on a JMS-T100GCV spectrometer in FD mode by Dr. Eri Fukushi and Mr. Yusuke Takata (GC-MS \& NMR Laboratory, Research Faculty of Agriculture, Hokkaido University). Melting points were measured on a Yamato MP21 and are uncorrected.

\section{Calculation}

DFT calculations were performed with the Gaussian $16 \mathrm{~W}$ program package. The geometries of the compounds were optimized by using the M06-2X method in combination with the $6-31 \mathrm{G}(\mathrm{d}, \mathrm{p})$ basis set. The coordinates are given in the Supporting Information.

\section{Synthetic Procedures}

A typical procedure for conversion of the precursor quinones to TCNQs is as follows: to a suspension of 6,7dimethylnaphtho[2,3-c][1,2,5]selenadiazole-4,9-dione $(2.53 \mathrm{~g}, 8.69 \mathrm{mmol})$ in dry $\mathrm{CH}_{2} \mathrm{Cl}_{2}(200 \mathrm{~mL})$ was added $\mathrm{TiCl}_{4}$ (4.67 g, $24.6 \mathrm{mmol}$ ). To the mixture was then added dropwise a solution of malononitrile $(8.11 \mathrm{~g}, 123 \mathrm{mmol})$ in a mixed solvent of dry pyridine $(20 \mathrm{~mL})$ and dry $\mathrm{CH}_{2} \mathrm{Cl}_{2}$ $(100 \mathrm{~mL})$ over $80 \mathrm{~min}$. After the mixture was stirred for $45 \mathrm{~h}$ at $25^{\circ} \mathrm{C}$, it was poured into $4 \mathrm{~N} \mathrm{HCl}$ aq $(400 \mathrm{~mL})$. The organic layer was separated and washed with water $(350 \mathrm{~mL} \times 5)$ and brine $(300 \mathrm{~mL} \times 3)$, and then dried over $\mathrm{Na}_{2} \mathrm{SO}_{4}$. Solvent was removed and the residue was chromatographed on silica gel $\left(\mathrm{CH}_{2} \mathrm{Cl}_{2}\right)$ to give $\mathbf{1 B}$ as a yellow solid (3.34 g) in 99\% yield. Similarly, 1C (orange crystal), 2B (yellow crystal), and 2C (orange crystal) were 
obtained in respective yields of $87 \%$ (224 mg), $74 \%$ (53 mg), and $82 \%$ ( $50 \mathrm{mg}$ ).

The selected spectral data for $\mathbf{1 B}, \mathbf{1 C}, \mathbf{2 B}$, and $\mathbf{2 C}$ are as follows. The spectral charts are given in the Supporting Information.

1B: $\mathrm{Mp} 272-280{ }^{\circ} \mathrm{C}(\mathrm{dec}) ;{ }^{1} \mathrm{H}$ NMR $\left(400 \mathrm{MHz}, \mathrm{CDCl}_{3}\right)$ $\delta=8.31(2 \mathrm{H}, \mathrm{s}), 2.49(6 \mathrm{H}, \mathrm{s}),{ }^{13} \mathrm{C} \mathrm{NMR}\left(100 \mathrm{MHz}, \mathrm{CDCl}_{3}\right)$ $\delta=155.22,152.24,144.89,130.59,126.79,113.35,112.68$, 84.07, 20.45; IR (ATR): 3155, 2957, 2226, 1602, 1554, 1441, 1402, 1284, 895, 751, 573, 480, $427 \mathrm{~cm}^{-1}$; HRMS-FD: $\mathrm{m} / \mathrm{z}$ $[\mathrm{M}]^{+}$calcd for $\mathrm{C}_{18} \mathrm{H}_{8} \mathrm{~N}_{6} \mathrm{Se}$ : 387.99764; found: 387.99670; UV/Vis $\left(\mathrm{CH}_{2} \mathrm{Cl}_{2}\right): \lambda_{\max }(\log \varepsilon)=364 \mathrm{sh}$ (4.47), 336 (4.58), 266sh (3.85), 252 (3.94), 230 (4.06) nm.

1C: $\mathrm{Mp}>400{ }^{\circ} \mathrm{C} ;{ }^{1} \mathrm{H}$ NMR $\left(400 \mathrm{MHz}, \mathrm{CDCl}_{3}\right) \delta=9.03(2$ $\mathrm{H}, \mathrm{s}), 8.11(2 \mathrm{H}, \mathrm{dd}, \mathrm{J}=6.2,3.2 \mathrm{~Hz}), 7.85(2 \mathrm{H}, \mathrm{dd}, \mathrm{J}=6.2$, $3.2 \mathrm{~Hz}),\left(400 \mathrm{MHz}, \mathrm{DMSO}-\mathrm{d}_{6}\right) \delta=9.11(2 \mathrm{H}, \mathrm{s}), 8.22(2 \mathrm{H}, \mathrm{dd}$, $\mathrm{J}=6.0,3.2 \mathrm{~Hz}), 7.89(2 \mathrm{H}, \mathrm{dd}, \mathrm{J}=6.0,3.2 \mathrm{~Hz}) ;{ }^{13} \mathrm{C}$ NMR $\left(100 \mathrm{MHz}, \mathrm{DMSO}-d_{6}\right) \delta=155.47,155.40,133.57,131.79$, 131.43, 129.90, 125.96, 115.13, 114.21, 82.88 ; IR (ATR): 3074, 2924, 2851, 2222, 1544, 1489, 1175, 914, 901, 768, 573, $469 \mathrm{~cm}^{-1}$; HRMS-FD: $m / z[\mathrm{M}]^{+}$calcd for $\mathrm{C}_{20} \mathrm{H}_{6} \mathrm{~N}_{6} \mathrm{Se}$ : 409.98200; found: 409.98257; UV/Vis $\left(\mathrm{CH}_{2} \mathrm{Cl}_{2}\right): \lambda_{\max }$ (log $\varepsilon)=452 \mathrm{sh}$ (3.80), 372 (4.43), 341 (4.72), 286sh (4.05), 258sh (4.13), 236 (4.60) nm.

2B: $\mathrm{Mp} 231-265{ }^{\circ} \mathrm{C}(\mathrm{dec}) ;{ }^{1} \mathrm{H}$ NMR $\left(400 \mathrm{MHz}, \mathrm{CDCl}_{3}\right)$ $\delta=8.42(2 \mathrm{H}, \mathrm{s}), 2.51(6 \mathrm{H}, \mathrm{s}),{ }^{13} \mathrm{C}$ NMR $\left(100 \mathrm{MHz}, \mathrm{CDCl}_{3}\right)$ $\delta=152.10,148.89,144.96,130.58,126.59,113.36,112.38$, 83.57, 20.43; IR (ATR): 3054, 2925, 2851, 2229, 1604, 1554, 1409, 1273, 975, 837, 734, 577, 525, $423 \mathrm{~cm}^{-1}$; HRMS-FD: $m / z$ [M] ${ }^{+}$calcd for $\mathrm{C}_{18} \mathrm{H}_{8} \mathrm{~N}_{6} \mathrm{~S}: 340.05311$; found: 340.05441 ; $\mathrm{UV} / \mathrm{Vis}\left(\mathrm{CH}_{2} \mathrm{Cl}_{2}\right): \lambda_{\max }(\log \varepsilon)=356(4.46), 318$ (4.49), 252sh (3.97), 230 (4.20) nm.

2C: $\mathrm{Mp} 361-362{ }^{\circ} \mathrm{C} ;{ }^{1} \mathrm{H}$ NMR $\left(400 \mathrm{MHz}, \mathrm{CDCl}_{3}\right) \delta=9.13$ $(2 \mathrm{H}, \mathrm{s}), 8.13(2 \mathrm{H}, \mathrm{dd}, \mathrm{J}=6.1,3.3 \mathrm{~Hz}), 7.57(2 \mathrm{H}, \mathrm{dd}, \mathrm{J}=6.1$, $3.3 \mathrm{~Hz}) ;{ }^{13} \mathrm{C}$ NMR could not be measured due to low solubility; Anal. calcd for $\mathrm{C}_{20} \mathrm{H}_{6} \mathrm{~N}_{6} \mathrm{~S}$ : C, 66.28; $\mathrm{H}, 1.67 ; \mathrm{N}$, 23.20\%. Found: C, 66.49; H. 1.89; N. 23.15\%; IR (ATR): 3076, 2925, 2853, 2223, 1590, 1543, 1487, 1443, 1249, 974, 914, 902, 845, 771, 580, 523, $470 \mathrm{~cm}^{-1}$; HRMS-FD: $m / z[\mathrm{M}]^{+}$ calcd for $\mathrm{C}_{20} \mathrm{H}_{6} \mathrm{~N}_{6} \mathrm{~S}$ : 362.03746; found: 362.03814 ; UV/Vis $\left(\mathrm{CH}_{2} \mathrm{Cl}_{2}\right): \lambda_{\max }(\log \varepsilon)=453 \mathrm{sh}$ (3.78), 350 (4.39), 324 (4.53), 270 (4.15), 232 (4.52) nm.

\section{Redox Potential Measurement}

Cyclic voltammetric analyses were conducted on a BAS ALS-600A electrochemical analyzer in dry $\mathrm{MeCN}$ containing $0.1 \mathrm{M} \mathrm{Et}_{4} \mathrm{NClO}_{4}$ as a supporting electrolyte. All of the values shown in the text are in $E / V$ vs. SCE measured at the scan rate of $100 \mathrm{mV} \mathrm{s}^{-1}$. Pt disk electrodes were used as the working and counter electrodes. All of the waves are reversible and the $E^{\text {red }}$ value was obtained as
$\left(E^{\text {cathodic peak }}+E^{\text {anodic peak }}\right) / 2$. Under the similar conditions, the potential for $\mathrm{Fe} / \mathrm{Fc}^{+}$is $+0.38 \mathrm{~V}$.

\section{X-Ray Analyses}

1B: $M F \mathrm{C}_{18} \mathrm{H}_{8} \mathrm{~N}_{6} \mathrm{Se}, F W$ 387.26, triclinic $P-1, a=8.7829$ (2) $\AA, b=9.6682(2) \AA, c=10.5357(2) \AA, \alpha=74.1400(19)^{\circ}$, $\beta=71.387(2)^{\circ}, \gamma=68.505(2)^{\circ}, V=776.37(3) \AA^{3}, \rho$ $(\mathrm{Z}=2)=1.657 \mathrm{~g} \mathrm{~cm}^{-3}$. A total of 7569 independent reflections $\left(2 \theta_{\text {max }}: 151.5^{\circ}\right)$ were measured at $150 \mathrm{~K}$ by using $\mathrm{CuK} \alpha$. The structure was solved by the direct method and the atomic coordinates were refined with anisotropic temperature factors. The positions of hydrogen atoms were calculated and included in the refinement with isotropic temperature factors. The final $R, w R$, and GOF values are $3.43 \%, 9.13 \%$, and 1.066 , respectively, for all data (CCDC 2048002).

1C: $M F \mathrm{C}_{20} \mathrm{H}_{6} \mathrm{~N}_{6} \mathrm{Se}, F W$ 409.27, triclinic $P-1, a=7.3955$ (3) $\AA, b=9.4496(4) \AA, c=12.4473(3) \AA, \alpha=86.492(3)^{\circ}, \beta$ $=78.650(3)^{\circ}, \quad \gamma=71.114(3)^{\circ}, \quad V=806.95(5) \quad \AA^{3}, \quad \rho$ $(\mathrm{Z}=2)=1.684 \mathrm{~g} \mathrm{~cm}^{-3}$. A total of 7907 independent reflections $\left(2 \theta_{\max }: 152.7^{\circ}\right)$ were measured at $150 \mathrm{~K}$ by using CuK $\alpha$. The structure was solved by the direct method and the atomic coordinates were refined with anisotropic temperature factors. The positions of hydrogen atoms were calculated and included in the refinement with isotropic temperature factors. The final $R, w R$, and GOF values are $4.66 \%, 11.53 \%$, and 1.047 , respectively, for all data (CCDC 2048003).

2B: $M F \mathrm{C}_{18} \mathrm{H}_{8} \mathrm{~N}_{6} \mathrm{~S}, F W$ 340.36, orthorhombic, Pca2 ${ }_{1}$, $a=12.18316(19) \AA, b=17.2162(3) \AA, c=7.28933(12) \AA$, $V=1528.92(4) \AA^{3}, \rho(Z=4)=1.479 \mathrm{~g} \mathrm{~cm}^{-3}$. A total of 4735 independent reflections $\left(2 \theta_{\max }: 151.6^{\circ}\right)$ were measured at $150 \mathrm{~K}$ by using $\mathrm{CuK} \alpha$. The structure was solved by the direct method and the atomic coordinates were refined with anisotropic temperature factors. The positions of hydrogen atoms were calculated and included in the refinement with isotropic temperature factors. The final $R, w R$, and GOF values are $5.54 \%, 14.88 \%$, and 1.203 , respectively, for all data (CCDC 2048004).

2C: $M F C_{20} \mathrm{H}_{6} \mathrm{~N}_{6} \mathrm{~S}, F W 362.37$, triclinic $P-1, a=7.3004(5)$ $\AA, b=9.4855(6) \AA, c=12.3573(6) \AA, \alpha=86.461(4)^{\circ}, \beta$ $=78.239(5)^{\circ}, \quad \gamma=71.110(6)^{\circ}, \quad V=792.62(9) \quad \AA^{3}, \quad \rho$ $(\mathrm{Z}=2)=1.518 \mathrm{~g} \mathrm{~cm}^{-3}$. A total of 7603 independent reflections $\left(2 \theta_{\max }: 151.6^{\circ}\right)$ were measured at $150 \mathrm{~K}$ by using CuKa. The structure was solved by the direct method and the atomic coordinates were refined with anisotropic temperature factors. The positions of hydrogen atoms were calculated and included in the refinement with isotropic temperature factors. The final $R, w R$, and GOF values are $5.20 \%, 15.12 \%$, and 1.109 , respectively, for all data (CCDC 2048005). 


\section{Funding Information}

We thank the Japan Society for the Promotion of Science Kakenhi (Nos. 19K15528, 20H02719, 20K21184). Financial supports from the Hattori Hokokai Foundation, Toyota Riken Scholar, the NOVARTIS Foundation (Japan) for the Promotion of Science, and the Orange Foundation for Hepatitis B Suit Hokkaido are gratefully acknowledged.

\section{Acknowledgment}

This work was also supported by the Research Program of "Five-star Alliance" in "NJRC Mater. \& Dev." MEXT.

\section{Supporting Information}

Following data are given in the Supporting Information: details of DFT calculations of 1B, 1C, 2B, and 2C; supplementary figures and table of X-ray analyses of $\mathbf{1 B}$, 1C, 2B, and 2C; spectral charts for 1B, 1C, 2B, and 2C. Supporting Information for this article is available online at https://doi.org/10.1055/s-0041-1725046.

\section{References}

(1) For pioneering reviews:. (a) Desiraju, G. R. Acc. Chem. Res. 1991, 24, 290. (b) Desiraju, G. R. Acc. Chem. Res. 1996, 29, 441. (c) Desiraju, G. R. Chem. Commun. 2005, 2995.

(2) (a) Huynh, H.-T.; Jeannin, O.; Fourmigué, M. Chem. Commun. 2017, 53, 8467. (b) Zhang, Y.; Wang, W. Crystals 2018, 8, 163. (c) Scilabra, P.; Terraneo, G.; Resnati, G. Acc. Chem. Res. 2019, 52, 1313.

(3) (a) Desiraju, G. R. Angew. Chem. Int. Ed. Engl. 1995, 34, 2311. (b) Nangia, A.; Desiraju, G. R. Acta Crystallogr. 1998, A54, 934. (c) Metrangolo, P.; Neukirch, H.; Pilati, T.; Resnati, G. Acc. Chem. Res. 2005, 38, 386. (d) Desiraju, G. R. J. Am. Chem. Soc. 2013, 135, 9952.

(4) For recent reviews: (a) Lim, J. Y. C.; Beer, P. D. Chem 2018, 4, 731. (b) Vogel, L.; Wonner, P.; Huber, S. M. Angew. Chem. Int. Ed. 2019, 58, 1880. (c) Kolb, S.; Oliver, G. A.; Werz, D. B. Angew. Chem. Int. Ed. 2020, 59, 22306. (d) Ho, P. C.; Wang, J. Z.; Meloni, F.; VargasBaca, I. Coord. Chem. Rev. 2020, 422, 213464.

(5) For early studies: (a) Werz, D. B.; Gleiter, R.; Rominger, F. J. Am. Chem. Soc. 2002, 124, 10638. (b) Werz, D. B.; Staeb, T. H.; Benisch, C.; Rausch, B. J.; Rominger, F.; Gleiter, R. Org. Lett. 2002, 4, 339. (c) Werz, D. B.; Gleiter, R.; Rominger, F. J. Org. Chem. 2002, 67, 4290. (d) Werz, D. B.; Gleiter, R.; Rominger, F. J. Org. Chem. 2004, 69, 2945. (e) Cozzolino, A. F.; Vargas-Baca, I.; Mansour, S.; Mahmoudkhani, A. H. J. Am. Chem. Soc. 2005, 127, 3184. (f) Cozzolino, A. F.; Vargas-Baca, I. J. Organomet. Chem. 2007, 692, 2654.

(6) (a) Wang, W.; Ji, B.; Zhang, Y.J. Phys. Chem. A 2009, 113, 8132. (b) Bauzá, A.; Quiñonero, D.; Deyà, P. M.; Frontera, A. CrystEngComm 2013, 15, 3137. (c) Pascoe, D. J.; Ling, K. B.; Cockroft, S. L. J. Am. Chem. Soc. 2017, 139, 15160. (d) Sánchez-Sanz, G.; Trujillo, C. J. Phys. Chem. A 2018, 122, 1369.

(7) (a) Tsuzuki, S.; Sato, N. J. Phys. Chem. B 2013, 117, 6849. (b) Lonchakov, A. V.; Rakitin, O. A.; Gritsan, N. P.; Zibarev, A. V.
Molecules 2013, 18, 9850. (c) Langis-Barsetti, S.; Maris, T.; Wuest, J. D. J. Org. Chem. 2017, 82, 5034. (d) Riwar, L.-J.; Trapp, N.; Root, K.; Zenobi, R.; Diederich, F. Angew. Chem. Int. Ed. 2018, 57, 17259. (e) Ams, M. R.; Trapp, N.; Schwab, A.; Milić, J. V.; Diederich, F. Chem. Eur. J. 2019, 25, 323.

(8) (a) Yamashita, Y.; Suzuki, T.; Mukai, T.; Saito, G. J. Chem. Soc., Chem. Commun. 1985, 1044. (b) Suzuki, T.; Yamashita, Y.; Kabuto, C.; Miyashi, T. J. Chem. Soc., Chem. Commun. 1989, 1102.

(9) (a) Klapötke, T. M.; Krumm, B.; Gálvez-Ruiz, J. C.; Nöth, H.; Schwab, I. Eur. J. Inorg. Chem. 2004, 4764. (b) Klapötke, T. M.; Krumm, B. Inorg. Chem. 2008, 47, 7025. (c) Berrueta Martínez, Y.; Rodríguez Pirani, L. S.; Erben, M. F.; Boese, R.; Reuter, G. C. G.; Vishnevskiy, Y. V.; Mitzel, N. W.; Della Védova, C. O. ChemPhysChem 2016, 17, 1463. (d) Berrueta Martínez, Y.; Rodríguez Pirani, L. S.; Erben, M. F.; Boese, R.; Reuter, C. G.; Vishnevskiy, Y. V.; Mitzel, N. W.; Della Védova, C. O. J. Mol. Struct. 2017, 1132, 175. (e) Previtali, V.; Sánchez-Sanz, G.; Trujillo, C. ChemPhysChem 2019, 20, 3186.

(10) (a) Kabuto, C.; Suzuki, T.; Yamashita, Y.; Mukai, T. Chem. Lett. 1986, 15, 1433. (b) Suzuki, T.; Kabuto, C.; Yamashita, Y.; Saito, G.; Mukai, T.; Miyashi, T. Chem. Lett. 1987, 16, 2285. (c) Suzuki, T.; Yamashita, Y.; Fukushima, T.; Miyashi, T. Mol. Cryst. Liq. Cryst. 1997, 296, 165.

(11) (a) Suzuki, T.; Kabuto, C.; Yamashita, Y.; Mukai, T.; Miyashi, T.; Saito, G. Bull. Chem. Soc. Jpn. 1987, 60, 2111. (b) Suzuki, T.; Kabuto, C.; Yamashita, Y.; Mukai, T.; Miyashi, T.; Saito, G. Bull. Chem. Soc. Jpn. 1988, 61, 483. (c) Suzuki, T.; Kabuto, C.; Yamashita, Y.; Mukai, T.; Miyashi, T. J. Chem. Soc., Chem. Commun. 1988, 895. (d) Suzuki, T.; Fujii, H.; Yamashita, Y.; Kabuto, C.; Tanaka, S.; Harasawa, M.; Mukai, T.; Miyashi, T. J. Am. Chem. Soc. 1992, 114, 3034. (e) Suzuki, T.; Fukushima, T.; Yamashita, Y.; Miyashi, T. J. Am. Chem. Soc. 1994, 116, 2793.

(12) Ishigaki, Y.; Asai, K.; Jacquot de Rouville, H.-P.; Shimajiri, T.; Heitz, V.; Fujii-Shinomiya, H.; Suzuki, T. Eur. J. Org. Chem. 2021, 990.

(13) Biot, N.; Bonafazi, D. Coord. Chem. Rev. 2020, 413, 213243.

(14) (a) Vishveshwara, S. Chem. Phys. Lett. 1978, 59, 26. (b) Sreerama, N.; Vishveshwara, S. J. Mol. Struct. THEOCHEM 1985, 133, 139. (c) Domagała, M.; Grabowski, S. J. J. Phys. Chem. A 2005, 109, 5683.

(15) (a) Dejiraju, G. R. J. Chem. Soc., Chem. Commun. 1989, 179. (b) Pedireddi, V. R.; Desiraju, G. R. J. Chem. Soc., Chem. Commun. 1992, 988.

(16) (a) Akasaki, Y.; Aonuma, H.; Kongo, K.; Sato, K.; Nukada, K.; Marumo, A. Jpn. Kokai Tokkyo Koho 1990, JP02097963A 19900410. (b) Yamashita, Y.; Tanaka, S.; Imaeda, K. Synth. Met. 1995, 71, 1965. (c) Shi, S.; Katz, T. J.; Yang, B. V.; Liu, L. J. Org. Chem. 1995, 60, 1285.

(17) (a) Lehnert, W. Tetrahedron Lett. 1970, 11, 4723. (b) Aumüller, A.; Hünig, S. Liebigs Ann. Chem. 1984, 618.

(18) (a) Schubert, U.; Hünig, S.; Aumüller, A. Liebigs Ann. Chem. 1985 1216. (b) Martin, N.; Hanack, M. J. Chem. Soc., Chem. Commun. 1988, 1522. (c) Gómez, R.; Seoane, C.; Segura, J. L. Chem. Soc. Rev. 2007, 36, 1305. (d) Bureš, F.; Bernd Schweizer, W.; Boudon, C.; Gisselbrecht, J.-P.; Gross, M.; Diederich, F. Eur.J. Org. Chem. 2008, 994. (e) Ishigaki, Y.; Sugawara, K.; Yoshida, M.; Kato, M.; Suzuki, T. Bull. Chem. Soc. Jpn. 2019, 92, 1211. (f) Ishigaki, Y.; Hayashi, Y.; Suzuki, T. J. Am. Chem. Soc. 2019, 141, 18293. (g) Ishigaki, Y.; Hashimoto, T.; Sugawara, K.; Suzuki, S.; Suzuki, T. Angew. Chem. Int. Ed. 2020, 59, 6581.

(19) Pauling, L. The nature of the chemical bond and the structure of molecules and crystals: An introduction to modern structural chemistry. 3rd ed; Cornell University Press: Ithaka, NY, 1960. 